\title{
Comparative studies on the digestive physiology of sheep fed on semi-purified or roughage-concentrate diets
}

\author{
2*. Microbiological investigations
}

\author{
By D. GIESECKE, M. J. LAWLOR† AND KARIN WALSER-KÄRST \\ Institut für Physiologie und Ernährung der Tiere, Universität München, Germany
}

(Received 24 November 1965-Accepted 30 December 1965)

\begin{abstract}
I. In a study of the microbial population in the rumen contents of sheep fed on a semipurified or a roughage--concentrate diet, the total counts and morphological groups of bacteria and protozoa, the counts of proteolytic, amylolytic and cellulolytic bacteria and the rates of breakdown of cellulose and starch in vitro were determined. Three sheep received each diet. 2. Protozoa disappeared completely from the rumen of sheep fed on the semi-purified diet. High counts of Entodinia persisted in the rumen of two sheep on the roughage-concentrate diet; a third animal was maintained defaunated on this diet. 3 . The mean total counts of bacteria per $g$ of rumen contents were $5 \times 10^{10}$ and $2.5 \times 10^{10}$ respectively in sheep fed on the semi-purified and roughage-concentrate diets and I I.4 $\times 10^{10}$ in the defaunated sheep. 4. The proportions of the morphological groups of bacteria and the counts of amylolytic bacteria were similar with both diets; the mean counts of proteolytic and cellulolytic bacteria were twice as high in the sheep on the semi-purified diet. The counts of all three functional groups of bacteria were considerably higher in the single defaunated sheep. 5. The mean rates of cellulose breakdown were 16.6 and $9.5 \mathrm{~g} / 1$. rumen fluid per $24 \mathrm{~h}$ for the sheep fed on the semi-purified and roughage-concentrate diets respectively. The corresponding rates of starch fermentation were 28 and $42 \cdot 4 \mathrm{~g} / \mathrm{l}$. rumen fluid per $24 \mathrm{~h}$. 6 . It is concluded that the bacterial population in the rumen of sheep fed on the semi-purified and the roughageconcentrate diets differed quantitatively rather than qualitatively. It is also concluded that the absence of protozoa, rather than a direct nutritive effect of the semi-purified diet, was responsible for the increased bacterial population in the rumen of the sheep fed on the semi-purified diet. The much higher bacterial counts in the rumen of the defaunated sheep support this view.
\end{abstract}

Numerous studies during the last two decades, recently reviewed by Koch (I964), clearly indicate that the total counts and functional groups of bacteria and protozoa present in the rumen vary with the composition of the diet given to the host animal. Very little microbiological information is available about ruminants fed on semipurified diets. It was, therefore, considered desirable to compare microbial population and function in the rumen of sheep fed on a semi-purified diet with those of sheep fed on a roughage-concentrate diet; these sheep were studied by Lawlor, Giesecke \& Walser-Kärst (1966). Since morphological grouping alone permits very limited conclusions concerning the biochemical activities of bacteria, differential viable counts of the principal physiological groupings (cellulolytic, amylolytic and proteolytic bacteria) were made using the appropriate media in conjunction with specific tests. The in vitro fermentation rates of cellulose and starch were also measured and the total counts and morphological groups of bacteria and ciliate protozoa were determined.

* Paper no. 1 : Br, $\mathscr{F}$. Nutr. (1966) 20, 373 .

$\uparrow$ Present address: The Agricultural Institute, Dunsinea, Castleknock, Co. Dublin, Ireland. 


\section{EXPERIMENTAL}

Animals and diets. Three 2-year-old crossbred wethers (B, D and $\mathrm{G}$ ) with rumen fistulas were fed on a semi-purified diet; three similar sheep (C, E and $H$ ) were fed on a pelleted roughage-concentrate diet. All sheep had constant access to food and water and were allowed an adjustment period of $4-6$ weeks on the diet. Details of the composition of the diets, daily food and water consumption, and other general aspects of the experimental procedure were reported by Lawlor et al. (1966). With the exception of sheep $\mathrm{H}$, all animals were fed on hay for some weeks before being placed on their respective diets. Sheep $\mathrm{H}$ received the semi-purified diet before the roughage-concentrate diet.

Sampling and dilutions. Samples of rumen contents for counts of ciliate protozoa were removed at $\mathrm{I} 0.00 \mathrm{~h}$ by suction through the rumen cannulas and pressed through four layers of surgical gauze. Representative samples of the rumen fluid were fixed with equal parts of $4 \%(\mathrm{v} / \mathrm{v})$ formaldehyde solution. Dilutions of the suspension were made with a solution of 2 parts of the phosphate buffer described by Coleman (I958) on I part glycerol. The nuclei were stained with acid methyl green, fifteen drops of a saturated solution being added per $100 \mathrm{ml}$ of the diluent solution. Samples of rumen contents for bacterial counts were taken between $\mathrm{I} 0.00$ and I $\mathrm{I} .00 \mathrm{~h}$ at weekly intervals over a 6-week period. Mixed rumen contents were removed by suction through the cannulas into a prewarmed $200 \mathrm{ml}$ polyethylene jar. The jar was filled to capacity, closed and immediately carried to the laboratory in a Thermos flask at $39^{\circ}$. The homogeneity of the rumen contents derived from both diets was good. The mixing of the rumen contents in a Waring Blendor and the subsequent serial dilutions were as described by Bryant \& Robinson (I96I). The diluent solution used was that of Bryant \& Burkey (1953).

Microscopic counts. A Sedgewick-Rafter counting chamber was used for protozoal counts. The cover glass was omitted and the samples were diluted to contain from ten to twenty-five cells per $\mathrm{mm}^{2}$. Each sample was counted in triplicate, fifty squares in each instance. The range of variation from the mean was found to be $\pm 2.5 \%$. In carrying out total counts of the rumen bacteria $0.01 \mathrm{ml}$ of the $1 \mathrm{O}^{-3}$ dilutions of rumen contents were spread over a square marked on a slide, stained with I $\%(w / v)$ safranin solution and counted as described by Giesecke ( 1960 ). The microscopic differentiation of the morphological types of rumen bacteria was performed on Gram-stained (Hallmann, I955) preparations of $2 \times 10^{-2}$ dilutions of rumen contents. A point counter was used to determine the proportions of the various morphological types.

Preparation and inoculation of media. All media were gassed with oxygen-free $\mathrm{CO}_{2}$ during preparation, dispensing and inoculation, and all manipulations including dilutions were carried out under a stream of $\mathrm{CO}_{2}$ by the technique of Hungate (1950). The $\mathrm{CO}_{2}$ was passed over hot reduced copper fillings to remove traces of oxygen. The media were prepared in round-bottomed flasks, the constituents listed below being added as solids or solutions. Autoclaving was carried out at $120^{\circ}$ for $15 \mathrm{~min}$. Starch, glucose, casein and cysteine hydrochloride were separately sterilized and added to the media before dispensing. The media were dispensed in $5 \mathrm{ml}$ portions into tubes which 
were then closed with rubber stoppers. Four tubes from each medium (see below) were inoculated with $0.1-0.3 \mathrm{ml}$ quantities of an appropriate dilution $\left(\mathrm{IO}^{-7}-\mathrm{IO}^{-9}\right)$ of the rumen contents. Roll tubes were prepared and incubated at $39^{\circ}$. The interval between sampling the rumen contents and starting the incubation of inoculated media was I 5-20 min.

Composition of media. The media were based on the mineral solutions of Bryant \& Burkey (I953). Solution (a) contained $\mathrm{KH}_{2} \mathrm{PO}_{4}, 3 \cdot 0 \mathrm{~g} / 1$.; solution $(b)$ contained (g/l.) $\mathrm{KH}_{2} \mathrm{PO}_{4}, 3 \cdot 0 ;\left(\mathrm{NH}_{4}\right)_{2} \mathrm{SO}_{4}, 6 \cdot 0 ; \mathrm{NaCl}, 6 \cdot 0 ; \mathrm{MgSO}_{4} \cdot 7 \mathrm{H}_{2} \mathrm{O}, 0 \cdot 6 ; \mathrm{CaCl}_{2} \cdot 2 \mathrm{H}_{2} \mathrm{O}, 0 \cdot 6$. The basal medium contained per $100 \mathrm{ml} 15 \mathrm{ml}$ of each of the mineral solutions $(a)$ and $(b)$, and the following constituents $(\mathrm{g} / 100 \mathrm{ml})$ : cysteine hydrochloride, 0.05 ; resazurin, 0.0001 ; agar, 2.0; $\mathrm{NaHCO}_{3}, 0.5$ and $\mathrm{Na}_{2} \mathrm{~S}_{2} \mathrm{O}_{4}, 0.003$. The bicarbonate and sodium dithionite were prepared as a combined solution and added as described by Blackburn \& Hobson (1962). The clarified rumen fluid (CRF) for addition to the media was prepared from freshly removed rumen contents by straining and centrifuging for $30 \mathrm{~min}$ at $\mathrm{I}_{5} 000 \mathrm{~g}$. For this purpose the contents were a composite sample from the three animals on the respective diets. For viable and differential viable counts three different solid media were prepared containing in addition to the basal medium the following constituents ( $\%)$.

Cellulose medium: cellulose (Solka Floc SW-40-A; Brown Co., New York, USA), sieved through a screen with 6400 meshes $/ \mathrm{cm}^{2}, 0.5$; cellobiose, 0.05; CRF, 30.0.

Starch medium: soluble starch (E. Merck, A. G., Darmstadt, Germany), 0.5; glucose $0.05 ; \mathrm{CRF} 20.0$.

Casein medium: casein Hammarsten (E. Merck, A. G., Darmstadt, Germany), 0.5 ; glucose, $0.05 ; \mathrm{CRF}, 20.0$.

Differential counts. The tubes containing the starch, casein or cellulose medium were, after inoculation, incubated for $7, I_{4}$ and 30 days respectively. Colonies were counted and the cellulolytic, amylolytic and proteolytic colonies were identified on the respective media by the zones of clearance around the colonies. For amylolytic colonies, flooding with iodine solution (Macpherson, I953) was used; on the casein medium the zones were clarified by treatment with a $10 \%(w / v)$ solution of trichloroacetic acid. The colonies thus identified are referred to as cellulolytic, amylolytic or proteolytic bacteria.

In vitro fermentation procedure. Rumen contents were removed at $10.00 \mathrm{~h}$, brought to the laboratory in a large Thermos flask at $39^{\circ}$ and strained through four layers of gauze. Portions of $20-25 \mathrm{ml}$ of the strained rumen fluid were added to equal amounts of mineral buffer solution (McDougall, r948). The cellulose substrate consisted of $500 \mathrm{mg}$ Solka Floc SW-40-A and the tubes were generally incubated for $24 \mathrm{~h}$. The substrate used for starch fermentation was $200 \mathrm{mg}$ rice starch, and incubation times were 4.5 and $9 \mathrm{~h}$. Samples were incubated in $100 \mathrm{ml}$ centrifuge tubes gassed with $\mathrm{CO}_{2}$ at a low rate and maintained at $39^{\circ}$ in a water-bath.

Cellulose determination. Cellulose was determined by the method of Huhtanen, Saunders \& Gall (I954), using $70 \%$ (w/v) sulphuric acid instead of $60 \%$ in the hydrolysation of the cellulose.

Determination of starch. After incubation, tubes were centrifuged for $10 \mathrm{~min}$ at 
$7500 \mathrm{~g}$ and the supernatant liquid was decanted. Water-soluble carbohydrates were removed from the residue by washing twice with warm $80 \%(\mathrm{v} / \mathrm{v})$ ethanol. The residue was then finely ground with kieselguhr and allowed to dry overnight at $60^{\circ}$. Pigments were removed from the resulting dried powder by diethyl ether extraction over $12 \mathrm{~h}$. The starch was then hydrolysed with $50 \mathrm{ml} \mathrm{N}$-sulphuric acid for $30 \mathrm{~min}$. The resulting glucose was determined photometrically by the method of McCready, Guggolz, Silviera \& Owens (1950).

\section{RESULTS}

The preliminary hay diet was intended to allow the development of a uniform microbial population in the rumen before the sheep were given the semi-purified and roughage-concentrate diets. Before the introduction of the experimental diets the protozoal populations were similar in all animals and consisted of about $84 \%$ Entodinia, $7 \%$ Diplodinia, $4.5 \%$ Dasytricha, $1.5 \%$ Isotricha and $0.5 \%$ Epidinia, with a total number averaging $\mathrm{I}_{5} \mathrm{O}-200 \times \mathrm{IO}^{3} / \mathrm{ml}$. In sheep $\mathrm{B}, \mathrm{D}$ and $\mathrm{G}$ all protozoa other than Entodinia disappeared from the rumen within 4 weeks of the change to the semi-purified diet. Subsequently the numbers of Entodinia decreased; after 8 weeks no protozoa were found in sheep D, and none were found in sheep B I week later. Sheep G was, however, not completely free of protozoa until the Igth week after the introduction of the semi-purified diet. Examination for the presence of protozoa was continued and it is important to note that the three animals remained completely defaunated during the remainder of the studies. An identical sequence of

Table I. Mean total counts with their standard errors of bacteria in the rumen contents of sheep fed on the semi-purified and roughage-concentrate diets

\begin{tabular}{ccc} 
Diet & Sheep* & $\begin{array}{c}\text { No. of } \\
\text { bacteria/g } \times 10^{-10}\end{array}$ \\
Semi-purified & B & $5.58 \pm 0.55$ \\
& D & $4.43 \pm 0.5 \circ$ \\
Roughage-concentrate & G & $5.23 \pm 0.60$ \\
& C & $2.08 \pm 0.07$ \\
& E & $2.94 \pm 0.44$ \\
& H & II.35 \\
& \multicolumn{3}{c}{ Six observations per sheep. }
\end{tabular}

defaunation was observed in sheep $H$ which was also given the semi-purified diet as a reserve animal during this period. After about 4 months on the semi-purified diet sheep $\mathrm{C}$ and $\mathrm{E}$, which had previously received hay, were given the roughage-concentrate diet. In order to maintain sheep $\mathrm{H}$ defaunated it was isolated from both the other animals, each of which had a protozoal fauna. Samples of rumen fluid from sheep $\mathrm{C}, \mathrm{E}$ and $\mathrm{H}$ were then periodically examined. The mean total counts of protozoa during this period were $7.9(2-15) \times 10^{5} / \mathrm{ml}$ in sheep $C$ and $52.4(15-97) \times 10^{5} / \mathrm{ml}$ in sheep E. In both, the fauna consisted almost entirely of Entodinia in proportions which fluctuated between 97 and $99.9 \%$. Very small numbers of Polyplastron were present. Sheep $\mathrm{H}$ remained free of protozoa throughout the period. A comparison of 
Vol. 20

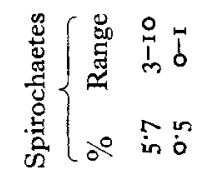

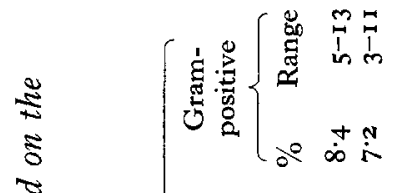

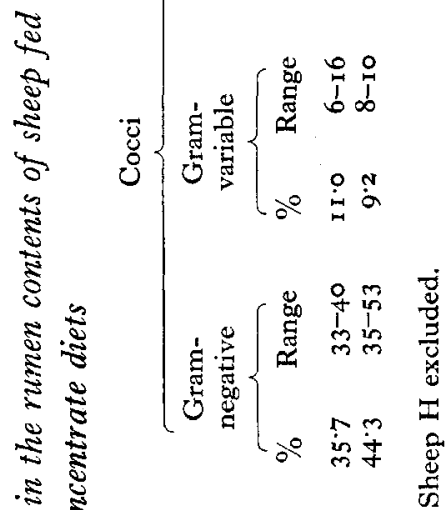

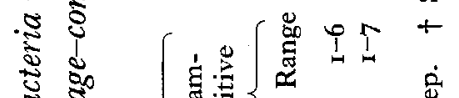

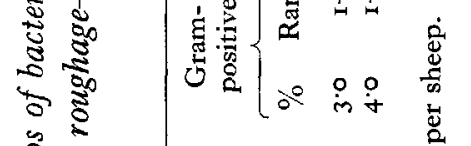

है कूष

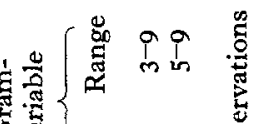

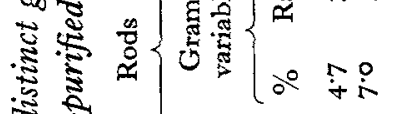

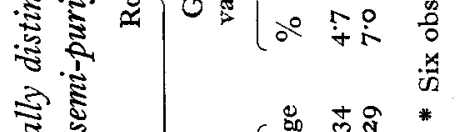

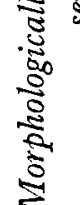

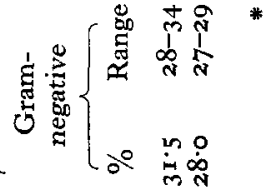

$\frac{\dot{0}}{\stackrel{0}{0}}$

ปู่

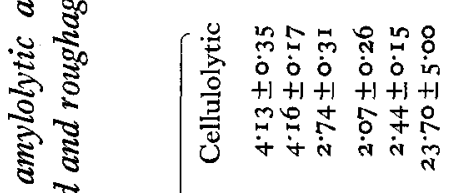

(i)

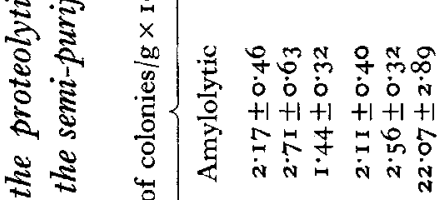

की

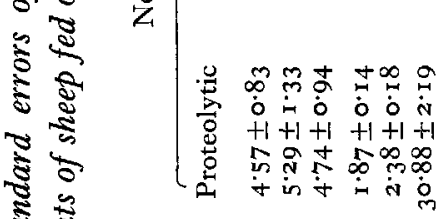

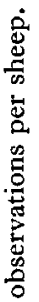

$+8$

*

$\frac{2}{2}$

डิ

$\stackrel{2}{2}$

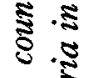

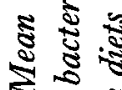

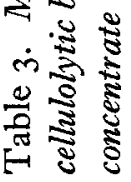

苍莺

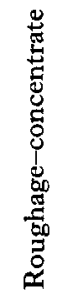

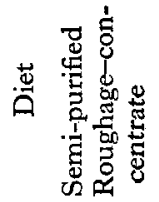


the total protozoal counts in sheep $\mathrm{C}$ and $\mathrm{E}$ during this period with those during the preliminary hay period showed that a considerable increase occurred when the pelleted roughage-concentrate diet was given.

The total counts of bacteria in the rumen contents of both groups of sheep are shown in Table I. It is evident from the table that, with the exception of sheep $\mathrm{H}$, the total counts were about twice as high in sheep receiving the semi-purified diet as in those on the roughage-concentrate diet. The relative proportions of the prinicipal morphological groups of bacteria are summarized in Table 2. The general bacteriological picture was quite uniform in the rumen contents of sheep on both diets, with Gram-negative organisms predominating. None of the large bacteria such as Oscillospira, Selenomonads and Quinn's ovals were found. The counts of the functional groups of bacteria cultured from the rumen contents of sheep receiving the semipurified and the roughage-concentrate diets are given in Table 3 . The proteolytic and cellulolytic bacteria in sheep $\mathrm{C}$ and $\mathrm{E}$ were about half as numerous as in sheep $\mathrm{B}$, $\mathrm{D}$ and $\mathrm{G}$. Counts of amylolytic bacteria were of the same range on both diets. The high counts of all three functional groups obtained from the defaunated sheep $\mathrm{H}$ are particularly remarkable.

Table 4. Mean rates with their standard errors of cellulose breakdown in rumen fluid incubated in vitro, from sheep fed on the semi-purified and roughage-concentrate diets

\begin{tabular}{|c|c|c|c|c|}
\hline Diet & Sheep & $\begin{array}{l}\text { No. of } \\
\text { observations* }\end{array}$ & $\begin{array}{l}\text { g cellulos } \\
\text { fluid } \mathrm{p}\end{array}$ & $\begin{array}{l}\text { e/l. rumen } \\
\text { ver } 24 \text { ht }\end{array}$ \\
\hline Semi-purified & $\begin{array}{l}\text { B } \\
D \\
G\end{array}$ & $\begin{array}{l}13 \\
13 \\
13\end{array}$ & $\left.\begin{array}{l}14.49 \pm 2 \cdot 05 \\
\mathrm{r} 6.94 \pm \mathrm{I} \cdot 58 \\
\mathrm{r} 8.46 \pm \mathrm{I} \cdot 73\end{array}\right\}$ & Mean, $16 \cdot 6_{3}$ \\
\hline Roughage-concentrate & $\begin{array}{l}\mathrm{C} \\
\mathrm{E} \\
\mathrm{H}\end{array}$ & $\begin{array}{l}5 \\
5 \\
5\end{array}$ & $\left.\begin{array}{r}12 \cdot 42 \pm \mathrm{I} \cdot 50 \\
8.28 \pm 0.89 \\
7.86 \pm \mathrm{r} \cdot 00\end{array}\right\}$ & Mean, 9.52 \\
\hline
\end{tabular}

* Each observation is a mean of three determinations.

$\uparrow$ The mean rate of cellulose breakdown, calculated from a total of twenty-seven observations on all sheep during the preliminary hay period, was $10.13 \pm 0.5 \mathrm{I} / \mathrm{g} /$. rumen fluid per $24 \mathrm{~h}$.

In some samples it was difficult to identify the clear zones around the colonies, especially with the proteolytic bacteria from sheep B, D and G. This was probably because the supernatant liquids of the centrifuged rumen fluid added to the media always remained somewhat turbid and were obviously responsible for the relatively high standard errors of the mean values for proteolytic bacteria from sheep B, D and G. The total colony counts were, in each instance, greater than the counts of the cellulose, starch and protein dissolving colonies. This observation suggested that the media used had a very limited selectivity. From the proteolytic, amylolytic and cellulolytic colonies, Gram-stained smears were prepared for microscopic examination. The three functional groups of bacteria were represented by five, three and four morphological types. The proportions of bacteria ascribed to these types indicated no striking differences between the two groups of sheep.

In Table 4 are given the mean rates of breakdown of cellulose in incubated rumen contents from the sheep fed on the semi-purified and roughage-concentrate diets; 
corresponding values for the preliminary hay period are included for comparison. It will be noted that the mean rates of in vitro cellulose fermentation were almost the same with the roughage-concentrate and hay diets. The mean rate of cellulose breakdown was significantly higher $(P<0.01)$ in samples from animals fed on the semi-purified diet. The rate of cellulose breakdown varied greatly between animals, particularly on the semi-purified diet. Thirteen in vitro determinations were carried out for each animal and the ranges in values were $3 \cdot 44^{-23} \cdot 60,4 \cdot 32-23 \cdot 16$ and $7 \cdot 16-28 \cdot 48 \mathrm{~g} / 1.24 \mathrm{~h}$ for sheep $B, D$ and $G$ respectively. There is little doubt that the variation in the consistency of the pressed rumen fluid resulted in this variation in the rate of cellulose breakdown.

Table 5. Mean rates, with their standard errors, of starch breakdown in rumen fluid, incubated in vitro, from sheep fed on the semi-purified and roughage-concentrate diets

$\left.\begin{array}{cccc}\text { Diet } & \text { Sheep } & \begin{array}{c}\text { No. of } \\ \text { observations* }\end{array} & \begin{array}{c}\text { g starch/l. rumen } \\ \text { fluid per } 24 \text { h } \dagger\end{array} \\ \text { Semi-purified } & \text { B } & 6 & 29 \cdot 82 \pm 5 \cdot 43 \\ & \text { D } & 4 & 30 \cdot 01 \pm 4 \cdot 39 \\ \text { Roughage-concentrate } & \text { G } & 7 & 25 \cdot 19 \pm 2 \cdot 52\end{array}\right\}$ Mean, 27.96

* Each observation is a mean of three determinations.

$\uparrow$ The mean rate of starch breakdown, calculated from a total twenty-three observations on all sheep during the preliminary hay period, was $14 \cdot 05 \pm \mathrm{r} \cdot 32 \mathrm{~g} / \mathrm{l}$. rumen fluid per $24 \mathrm{~h}$.

If the extremely low values caused by fluctuations in the consistency of the inoculum are excluded, then the remaining $80 \%$ of the determinations give an overall average rate of fermentation of $19.12 \mathrm{~g} / \mathrm{l}$. rumen fluid $24 \mathrm{~h}$. Repeatability of the results was quite good with the sheep given the roughage-concentrate diet, and the standard errors quoted refer to five determinations. A number of determinations were carried out comparing the rate of cellulose breakdown over 12 and $24 \mathrm{~h}$, using rumen fluid from animals on both diets. The results showed that in rumen fluid from animals fed on the semi-purified diet over $85 \%$ of the cellulose was fermented in vitro after $12 \mathrm{~h}$, and $50 \%$ in $\mathrm{I} 2 \mathrm{~h}$ in rumen fluid from the animals given the roughage-concentrate diet. An incubation time of $\mathrm{I} 2 \mathrm{~h}$ was not adopted, however, since the variation in results, arising from the variable consistency of the rumen fluid from sheep $B, D$ and $G$, tended to be greatest during incubation periods of $12 \mathrm{~h}$.

Results of the studies on the rates of fermentation of starch are given in Table 5. The rates obtained for the sheep given the roughage-concentrate diet were significantly greater $(P<0.01)$ than for those given the semi-purified diet. There was, however, as shown by analysis of variance, a large variation $(P<0.05)$ between animals particularly in the values obtained for sheep receiving the roughage-concentrate diet. 


\section{DISCUSSION}

The most significant effect of the semi-purified diet on the rumen microbial population was probably the complete disappearance of ciliate protozoa. The reasons for this defaunation are not clearly understood. The mean $\mathrm{pH}$ of the rumen contents throughout the experimental periods was 5.67 and 5.54 for the sheep fed on the semipurified and roughage-concentrate diets respectively. This seems to rule out the possibility that a persisting low $\mathrm{pH}$ caused the disappearance of the protozoa from the rumen of the animals given the semi-purified diet. Christiansen \& Burroughs (1962) postulated that a high rate of passage of the rumen digesta was responsible for the disappearance of the ciliate protozoa from the rumen of sheep fed on a pelleted diet. This seems unlikely to have been the explanation in our experiments since the roughage-concentrate diet supported a protozoal population, although this diet was consumed in amounts which must have resulted in markedly higher rates of flow of digesta than with the semi-purified diet.

The total counts of bacteria in the rumen contents of the sheep given the semipurified diet were in substantial agreement with those reported by Gall, Thomas, Loosli \& Huhtanen (195I) for sheep maintained on a semi-purified diet which contained casein, Cellophane and wheat straw. Gall et al. found Gram-positive cocci to be highly predominant in the flora, a result very different from our observations. The percentage of the morphological groups of bacteria reported here for both groups of sheep confirm the observations of Blackburn \& Hobson (I960). A predominance of Gram-negative cocci and rods seems typical for a normal rumen population. For instance Brüggemann \& Giesecke ( 1963 ) studied the rumen flora of bulls on a roughage-concentrate diet, and found it to contain $60-65 \%$ of Gram-negative cocci and $9 \%$ of Gram-negative rods. Furthermore, Warner (1962) reported about 70 and $15 \%$ respectively of these two morphological groups present in the rumen of grazing sheep. Compared to these observations the percentages of Gram-negative cocci seemed to be reduced in favour of Gram-negative rods in the studies now presented.

Exceptionally high bacterial counts were obtained in samples from sheep $\mathrm{H}$ compared to those from the other sheep on the same diet. The absence of protozoa from the rumen of this animal appeared to be the most probable explanation for the difference in bacterial counts. The observation that a higher population of rumen bacteria is maintained in defaunated ruminants is supported by studies of Bryant \& Small ( 1960 ), who reported a marked drop in cellulolytic bacteria in defaunated calves after inoculation with rumen contents containing protozoa. More direct results were obtained by Eadie \& Hobson (1962) from defaunated sheep in which the small rumen bacteria decreased by about $50 \%$ after inoculation with protozoa, whereas the counts of large bacteria remained almost unaffected. Thus the apparent competition between protozoa and bacteria for certain nutrients suggested by these authors seems. a reasonable explanation for the present observations.

From earlier studies by Hungate (1957) and Bryant \& Burkey (1953) it appears that only $10 \%$ or less of the total flora were viable. In the present study the proteolytic, amylolytic and cellulolytic bacteria accounted for about 22 and $27 \%$ of the total 
bacteria present in the rumen contents of sheep given the semi-purified diet and in those of sheep $\mathrm{C}$ and $\mathrm{E}$ respectively. The corresponding value for sheep $\mathrm{H}$ was $68 \%$. Evidently a considerable proportion of bacteria does not hydrolyse either cellulose, starch or casein.

The rates of cellulose fermentation in vitro observed with inoculum from sheep receiving the hay or the roughage-concentrate diet agree reasonably with the value of Io $\mathrm{g} / \mathrm{l}$. per day reported by Warner (1956). In the present experiments and those of Warner the average daily consumption of cellulose by the sheep was somewhat less than $200 \mathrm{~g} /$ day. The increased rate of cellulose breakdown in vitro, with inoculum from sheep on the semi-purified diet, was probably related to the higher counts of cellulolytic bacteria in the rumen of these animals. The semi-purified diet supplied $35^{\circ} \mathrm{g}$ cellulose daily. The greater intake of cellulose is likely to have stimulated the growth of cellulolytic bacteria in the rumen.

The rate of starch fermentation recorded in vitro with a diet of hay agrees very well with the value of $\mathrm{x} 2 \mathrm{~g} / 1 . / 24 \mathrm{~h}$ which was found by Warner (1956) with rumen contents from sheep fed on hay. Furthermore, the rate of $48 \mathrm{~g} / 1 . / 24 \mathrm{~h}$ which this author reported for contents from sheep on a roughage-concentrate ration is in good agreement with our mean result. The large differences in the rates of starch fermentation between the individual sheep fed on the roughage-concentrate diet in our experiments seem to reflect the differences in the microbial population. Contents from sheep $\mathrm{C}$, which had the lowest rate of starch breakdown in vitro, had also the lowest count of amylolytic bacteria and a correspondingly small population of rumen ciliate protozoa. The very large protozoal count (mainly Entodinia) in the rumen contents of sheep $\mathrm{E}$ seemed most likely to be responsible for its very high rate of starch fermentation.

It is concluded from the criteria studied that the semi-purified diet supported a rumen microbial population and function similar to those of the rumens of animals given a ration of a more usual type. The more important differences observed with the semi-purified diet were the absence of protozoa in the rumen, the size of the bacterial population and the very low rate of secretion of parotid saliva. The importance of these differences would depend on the nature of the studies being conducted with the semi-purified diet.

One of us (M.J.L.) is greatly indebted to the Alexander von Humboldt-Stiftung for the fellowship award to carry out this work. Thanks are due to Professor Dr Dr Johs. Brüggemann for providing the facilities in his Institute and for his advice and encouragement. We thank Miss Jutta Demme for valuable assistance.

\section{REFERENCES}

Blackburn, T. H. \& Hobson, P. N. (1960). F. gen. Microbiol. 22, 290.

Blackburn, T. H. \& Hobson, P. N. (1962). F. gen. Microbiol. 29, 69.

Brüggemann, J. \& Giesecke, D. (1963). Z. Tierphys., Tierernähr, u. Futtermittelk. I8, 215.

Bryant, M. P. \& Burkey, L. A. (1953). F. Dairy Sci. 36, 205.

Bryant, M. P. \& Robinson, I. M. (196r). F. Dairy Sci. 44, I 446.

Bryant, M. P. \& Small, N. (r96o). F. Dairy Sci. 43, 654 .

Christiansen, W. C. \& Burroughs, W. (1962). F. Anim. Sci. 21, 990.

Coleman, G. S. (1958). Nature, Lond., 182, I 104. 
Eadie, J. M. \& Hobson, P. N. (1962). Nature, Lond., 193, 503.

Gall, L. S., Thomas, W. E., Loosli, J. K. \& Huhtanen, C. N. (195I). F. Nutr. 44, I13.

Giesecke, D. (1 960). Zentbl. Bakt. Parasit. Abt. I, 179, 448.

Hallmann, L. (1955). Bakteriologie und Serologie, 2nd ed., p. 760. Stuttgart: Georg. Thieme Verlag.

Huhtanen, C. N., Saunders, R. K. \& Gall, L. S. (1954). F. Dairy Sci. 37, 328.

Hungate, R. E. ( 1950 ). Bact. Rev. 14, I.

Hungate, R. E. (I957). Can. F. Microbiol. 3, 289.

Koch, G. (1964). Z. Tierphys. Tierernähr. u. Futtermittelk. 19, 24.

Lawlor, M. J., Giesecke, D. \& Walser-Kärst, K. (1966). Br. F. Nutr. 20, 373.

McCready, R. M., Guggolz, J. Silviera, V. \& Owens, H. S. (r950). Analyt. Chem. 22, r 56.

McDougall, E. I. (1948). Biochem. F. 43, 99.

MacPherson, M. J. (1953). F. Path. Bact. 66, 95.

Warner, A. C. I. (1956). F. gen. Microbiol. 14, 527.

Warner, A. C. I. (1962). F. gen. Microbiol. 28, I 19. 